\title{
7 Positive approaches to childhood sexuality and transforming gender norms in Malawi
}

\author{
Godfrey Dalitso Kangaude
}

\section{Introduction}

Adolescence is a critical stage of human development. The decisions made, and behaviours formed at this stage, have a lasting impact on the life trajectory of an individual. ${ }^{1}$ Gender norms shape the experience of biological changes associated with puberty such as the development of secondary sexual characteristics and the social changes associated with new roles ascribed at the emergence of adolescence. These gender norms shape social behaviours of adolescents including how they form social relationships and engage in sexual practices, and later reproductive practices. The Global Early Adolescent Survey (GEAS), also implemented in Malawi, showed that gender norms begin to exert a strong influence on very young adolescents (VYAs) from the age of $10 .^{2}$ Behaviours and practices appear during adolescence that differentially shape the developmental trajectories of boys and girls. Girls experience mortality and morbidity related to reproductive health such as complications of early pregnancies and unsafe abortions. Boys, on the other hand, experience a different set of challenges such as road injuries and interpersonal violence. ${ }^{3}$ However, girls are more likely than boys to experience harmful practices such as child marriage, human trafficking, and all forms of gender-based violence including physical, sexual and emotional violence. Gender inequitable norms underlie this disproportionate distribution of sexual and reproductive health burdens between boys and girls.

Most societies including in Malawi perceive children and VYAs as asexual or assume that sex and sexuality do not matter to children. ${ }^{4}$ When adolescents begin to express sexual and romantic interests, parents react with anxiety and fail to communicate openly with their child about sex and sexuality, or are mostly worried about the negative consequences of sexual activity for girls. ${ }^{5}$ Because gender and sexuality are inextricably linked, failure to positively and openly communicate with adolescents about sexuality also implies that gender inequitable norms that shape early relationships in adolescence are not addressed. ${ }^{6}$ For instance, the GEAS revealed that romantic relationships between VYAs in Malawi are common, but there is already a high prevalence of intimate partner violence (IPV). ${ }^{7}$ 
Inequitable gender norms consolidate when adolescents start to experience sexual feelings and engage in sexual relationships. ${ }^{8}$ Evidence suggests that early adolescence is an opportune time to encourage positive sexual practices and gender-equitable norms, and this has immediate benefits but also over the life course. ${ }^{9}$ An important prerequisite, therefore, is to recognize children and adolescents as evolving sexual beings. A positive approach toward childhood sexuality is critical to addressing gender inequality which would also contribute to improved sexual health and wellbeing beyond adolescence.

The global agendas to address gender inequality and promote human and child rights motivate this chapter. The following highlight from paragraph 7.34 of the Program of Action (PoA) of the 1994 International Conference on Population and Development (ICPD) is especially salient:

Human sexuality and gender relations are closely interrelated and together affect the ability of men and women to achieve and maintain sexual health and manage their reproductive lives. Equal relationships between men and women in matters of sexual relations and reproduction, including full respect for the physical integrity of the human body, require mutual respect and willingness to accept responsibility for the consequences of sexual behaviour. Responsible sexual behaviour, sensitivity and equity in gender relations, particularly when instilled during the formative years (emphasis supplied), enhance and promote respectful and harmonious partnerships between men and women.

This exhortation of the ICPD PoA is read with aspirations articulated in Sustainable Development Goal 5 of United Nation's (UN) Agenda 2030 which calls on states to achieve gender equality and to empower women and girls. It is also read with Goal 17 of African Union's (AU) Agenda 2063 to achieve gender equality in all spheres of life. The African Committee of Experts on the Rights and Welfare of the Child (ACERWC) published Africa's Agenda for Children 2040, describing ten aspirations based on recognition of the role of children in shaping Africa's development, and therefore, the importance of protecting and realizing the rights of children.

Malawi has ratified human rights treaties including the United Nation's Convention on the Rights of the Child (UNCRC), the African Charter on the Rights and Welfare of the Child (ACRWC), the Convention on the Elimination of All Forms of Violence Against Women (CEDAW), and the Protocol to the African Charter on Human and Peoples' Rights on the Rights of Women in Africa (Maputo Protocol). Malawi has also taken steps to address gender inequality by enacting laws such as the Gender Equality Act (GEA).

Based on the evidence from the GEAS of the influence of gender norms on VYAs, Promundo and the College of Medicine (Malawi) developed a curriculum aimed at transforming gender inequitable norms for VYAs including in interpersonal relationships. ${ }^{10}$ In a similar vein, this chapter draws upon evidence and insights from the life course perspective of individual development, and is inspired by Malawi's obligations and commitments under international 
law and regional and global agreements, to discuss positive approaches to childhood sexuality to address gender inequitable norms for children and VYAs.

\section{Understanding the sexual and gendered world of the child and adolescent}

\subsection{Gender, sexuality and the life course}

A life course perspective conceptualizes individual life courses as composed of multiple and simultaneously occurring interdependent trajectories through various dimensions of life such as sexuality, family and work. ${ }^{11}$ A trajectory is a pathway through one's life extending from birth to death, and is made up of a sequence of life events and transitions. An event is a relatively abrupt change or occurrence, for instance, first sexual intercourse, while a transition is a gradual change from one social role to another, for example, from childhood to adolescence. ${ }^{12}$ The life course has contributed to understanding sexuality development in the transition from childhood to adolescence.

First, early sexual experiences influence sexual attitudes and behaviour at a later stage in life, for example, it has been shown that coercive experiences at sexual debut are associated with sexual risks in the life course. ${ }^{13}$ The period of adolescence can cushion against or exacerbate childhood experiences, allowing for accumulation of prior advantage or disadvantage, thereby launching the adolescent into a sexual health trajectory that is on one hand unique for the individual, and on the other hand shares common characteristics with the trajectories of peers. ${ }^{14}$

Second, an individual's sexual biography is shaped by social, cultural and historical forces. For instance, to appreciate the social attitudes toward sexuality of adolescent girls in Malawi, one should understand the complex interaction of colonial laws, religious beliefs and social norms. ${ }^{15}$

A third insight is that life is not determined entirely by external forces. Individuals do exercise agency to determine their trajectory, because 'young people select into personal experiences, interpersonal relationships, and social settings in ways that reflect their past and contribute to their futures'. ${ }^{16}$ Individuals may be influenced by external forces, but they are also self-determining and responsible for shaping their sexual and gendered behaviours.

Finally, gender and sexuality are mutually constitutive in the life course. As Carpenter and Delamater has stated: 'Throughout the life course, transitions in an individual's sexual and sexual identity trajectories will affect his gender trajectory, even as the gender-related transitions that he experiences help to construct his sexual and sexual identity trajectories'. ${ }^{17}$ A good example is that boys learn to associate masculinity with sexual prowess so that sexual aggression is perceived as a mark of manhood. ${ }^{18}$

\subsection{The invisible process of learning sexuality}

Most adults believe that sexuality (and gender) does not concern children until they are older. ${ }^{19}$ Most parents have difficulty in communicating expressly with 
children and adolescents about sex and sexuality. ${ }^{20}$ However, as shall be further explored later in the chapter, communication about sex and sexuality between parents and children also takes place invisibly. In fact, people invest in or legitimize particular power relations without being conscious of or being aware of their actions. ${ }^{21}$ As Pierre Bourdieu has put it, '[i]t is because subjects do not, strictly speaking, know what they are doing that what they do has more meaning than they know'. ${ }^{22}$ Parents and adults, both intentionally and unawares, instil in children norms and values that influence early sexual behaviours and practices, and relationships of power.

This part of the chapter draws mostly from Simon and Gagnon's Sexual conduct: The social sources of human sexuality in which they explain how this social learning takes place leading to the emergence of sexual identity at adolescence. ${ }^{23}$ The authors make an important point that adolescence is linked to the preceding stage of infancy because "we do not become sexual all at once at puberty; there is a significant level of continuity with the past'. ${ }^{24}$ Experiences occur in infancy, even before the acquisition of language, that influence sexuality development later in the life course. These experiences are not necessarily sexual in character because they will influence other aspects of the infant's development in addition to sexual development. ${ }^{25}$

According to Simon and Gagnon, there are two important experiences in the years running up to puberty that influence development of sexual identity:

The first of these is the pattern of naming the child's behaviors in general and the specific adult reaction to behaviors that are conceived to be sexual. The second is the continued building of conventional gender identities based on preverbal social decision about the gender of the child. ${ }^{26}$

In these experiences, parents and caregivers play a significant role in the child's learning process. Parents tend to be reactive when dealing with the behaviour of a child interpreted by the parents as sexual. Parents react to cues such as use of words or actions of the child which they read or define as sexual. Parents employ several strategies as a response to what they perceive is sexual behaviour. They may 'describe the behavior as sexual and say that it is wrong, may mislabel the behavior, describing it as something it may not be, or may nonlabel the behavior by ignoring or providing a judgment without a specific label'. ${ }^{27}$ So, for instance, a parent may tell their daughter to 'sit properly' or reprimand her for showing interest in a boy, but would rarely explain to the child the meaning of the parental concerns. When parents take such action that is motivated by their belief about sexuality, they rarely describe it in sexual terms but rather in moral terms using expressions or commands such as 'dirty', 'bad', 'stop', 'good girls don't...', and in so doing endowing the behaviour with moral significance that indirectly shapes its sexual meaning. ${ }^{28}$ It is also in the difference in how parents react to boys and girls that the child learns what is appropriate feminine and masculine (sexual) behaviour. ${ }^{29}$ 
In most cases, the child does not understand or fully understand the meaning of the actions or reactions of adults, because adults perceive the sexual behaviour of the child in adult terms. The child is therefore exposed to "judgments and responses that follow from the application of a sexual vocabulary that they do not know' ${ }^{30}$ Simon and Gagnon also describe the reverse situation, whereby the child is exposed to sexual vocabulary but without at first associating it with sexuality, for instance, a child might first learn to use the word 'fuck' but only later on learn its sexual meaning. In the process of becoming sexual, therefore, the child on the one hand learns from experiences that are judged in certain ways, but also learns words before experiences to which they refer. This creates a dilemma because '[t]he possession of words, experiences, and judgments, all unassembled, leaves the young child without a vocabulary with which to describe his emerging physical or psychic experiences' ${ }^{31}$ Typically, therefore, information on sexuality during childhood is provided by adults through judging perceived sexual behaviour but without naming it, so that children understand things largely in terms of what they ought not to do. Children adapt by piecing together fragments from these parental moral injunctions and actions which then become the basis for early learning experiences of children which shape children's attitudes and values toward sexuality. ${ }^{32}$

Therefore, parents communicate to children about sexuality and gender in two modes: expressly where the messages about sexuality are explicit, and invisibly through the parents' action or nonaction, and reaction or nonreaction to what they perceive is sexual behaviour of the child. Failure of parents to talk about sexuality to the adolescent is itself communication about sexuality. In most cases, because of underlying beliefs and norms, parents communicate sexuality as negative, especially to girls, so that the child learns to associate sexuality with shame, guilt and secrecy. ${ }^{33}$

\subsection{An example of sexual conduct of adolescents shaped by gender norms}

Gender inequitable norms learned in the family find expression in school cultures. This section briefly discusses gender discrimination using a study conducted by Muhanguzi in Uganda, in which she interviewed girls and boys about sexual behaviours and practices. The study results revealed that gender norms influence societal expectations creating a double standard for girls. Boys expected that a 'good' girl would show modesty when a boy proposed to her. A girl should not say 'yes' too quickly or enthusiastically because the boys would consider her a slut. ${ }^{34}$ In other words, the girl should suppress her sexual desire. However, boys also expected girls to acquiesce to love or sex proposals from boys. Boys would respond with violence and abuse to those girls that resisted their advances. This created a double standard because of the expectation that a girl should simultaneously reject and accept the invitations of the boy. ${ }^{35}$ The double standard diminishes the power of girls to exercise choice about sexuality and to negotiate safe sex. It also justifies violence from boys when girls try to assert themselves. ${ }^{36}$ 
Girls learn sexual passivity early in life. ${ }^{37}$ The norm has wide implication, for instance, an evaluation of the Youth Friendly Health Services in Malawi showed that 'many girls who would have requested condoms failed to do so for fear of being labelled sex workers' ${ }^{38}$ Another study in Malawi also showed that parents are biased towards the education of girls because of the belief that girls are sexually weak and would end up being impregnated by boys. ${ }^{39}$

Malawi has put in place various laws and policies to address gender inequality including the GEA. However, to tackle gender inequalities children learn in the parent/child relationship and to positively influence the sexual relationships of adolescents requires that adults first recognize and accept the evolving sexual agency of children and adolescents.

\section{Transforming childhood sexuality and gender norms through the legal framework}

\subsection{The Gender Equality Act and Section 19 rights}

Malawi's enactment of the GEA in 2013 is an important expression of its commitment to its obligations to address the negative impact of gender norms. The GEA aims to advance gender equality by prohibiting harmful practices, sex discrimination and sexual harassment, promoting gender non-discriminatory access to employment, education and training, and recognizing sexual and reproductive health rights. In this chapter, the discussion focuses on applying the concept of sexual and reproductive health rights to advance positive approaches to childhood and adolescent sexuality. To achieve this, it is necessary to understand the genesis of Section 19 of the GEA.

Section 19 (1) of the GEA provides that

Every person has a right to adequate sexual and reproductive health which includes (emphasis supplied) the right to

(a) access to sexual and reproductive health services;

(b) access to family planning services;

(c) to be protected from sexually transmitted infection;

(d) self-protection from sexually transmitted infection;

(e) choose the number of children and when to bear those children;

(f) control fertility; and

(g) choose an appropriate method of contraception.

However, the use of the term 'includes' suggests that the list is not exhaustive. But then, what is the expansive list? Further, what influenced the choice of the list? The answer to the first question is in the report on the development of the GEA by the Malawi Law Commission (MLC), the body responsible for developing the GEA. Drawing on various authoritative instruments, the MLC recognized that sexual and reproductive health 'requires a positive and respectful approach to sexuality and sexual relationships, as well as the possibility of 
having pleasurable and safe sexual experiences, free of coercion, discrimination and violence'. Further, '[f]or sexual and reproductive health to be attained and maintained, the sexual rights of all persons (emphasis supplied) must be respected, protected and fulfilled'. The MLC defined sexual rights as:

[A] subset of human rights that are already recognized in national laws, international human rights law and other consensus statements. They include the right of all persons, free of coercion, discrimination and violence, to

(a) the highest attainable standard of sexual health, including access to sexual and reproductive health care services;

(b) seek, receive and impart information related to sexuality;

(c) sexuality education;

(d) respect for bodily integrity;

(e) choose their sexual partner;

(f) decide to be sexually active or not;

(g) have consensual sexual relations;

(h) enter into consensual marriage;

(i) decide whether or not and when, to have children; and

(j) pursue a satisfying, safe and pleasurable sexual life.

Interestingly, when articulating the list of rights in Section 19 of the draft bill it proposed, the MLC did not use the list under the sexual rights concept it discussed in its report. Rather, it appears to have followed the list under the concept of sexual and reproductive health rights as stipulated in the ICPD PoA which emphasizes reproductive health rights. The challenge is that reproduction, and even 'health', are not the main concern for children and VYAs. Early experiences of sexuality are mostly to do with non-reproductive aspects, such as curiosity about their bodies, forming romantic partnerships and nonpenetrative sexual conduct. The list of sexual rights that the MLC did not explicitly include in Section 19 such as the right to sexuality education, the right to choose a sexual partner and the right to decide to be sexually active or not, are precisely the ones that are critically important for children and VYAs. ${ }^{40}$

The MLC did not list these sexual rights, most likely to avoid controversy. Conservative and influential groups such as the Holy See adopt the position that sexual rights should not extend to children and unmarried adolescents. ${ }^{41}$ Indeed, Malawi and other African countries, have previously rejected the notion of the right to sexuality education when it was proposed by the former UN Special Rapporteur on Education. ${ }^{42}$

Nevertheless, Section 19 of the GEA is progressive for recognizing sexual and reproductive rights. This author argues that Section 19 rights should be interpreted to include the unlisted sexual rights on the basis that this is what the MLC, in proposing the bill that became enacted as the GEA, had intended in conceiving the provision, and this intention was assumed by parliament when it 
passed the bill into law. The evidence is in the travaux préparatoires that include MLC's report of the development of the GEA. Further, Section 19 deliberately uses the term 'include' to mean that the express list is not exhaustive. This author argues, therefore, that a court interpreting Section 19 could be persuaded to determine that sexual rights are applicable in Malawi and are recognized for every person including children.

Despite Section 19 being progressive, the invisibility of the unlisted rights makes it difficult for them to be accessed and applied. The route to confirm their application would be through the interpretation of a tribunal such as the national courts or treaty monitoring bodies. This chapter will explore what some of the UN and AU treaty monitoring bodies have said regarding childhood sexuality and gender to argue that state and intergovernmental institutions should adopt positive approaches to addressing childhood sexuality and gender.

\subsection{Positive discourses on childhood and adolescent sexuality in treaty monitoring bodies}

The author reviewed general comments and recommendations issued by UN and $\mathrm{AU}$ treaty monitoring bodies, and especially looked for positive language about childhood sexuality, that is, language that recognizes the child as having sexual agency.

Human rights instruments including the UNCRC and ACRWC do not expressly mention sexuality. However, the UN and AU Committees have interpreted and analyzed various provisions relating to childhood sexuality. The dominant discourses about sexuality construct children as powerless and victims. ${ }^{43}$ Undeniably, children and adolescents are more vulnerable to sexual harms than adults. However, to address these harms and the underlying norms that fuel these, children should be recognized as sexual beings with an evolving capacity for ethical sexual exploration, negotiation and pleasure. ${ }^{44}$

The UN and AU treaty documents reflect the dominant constructions of child as lacking sexual agency. Few texts use language that acknowledges sexual agency of children and adolescents. Those texts that recognize sexual agency still draw on discourses of victimhood and vulnerability to sexual abuse, violence and HIV/AIDS. Table 7.1 presents some texts from the Committee on the Rights of the Child (CRoC), the African Commission on Human and Peoples' Rights (ACHPR) and the ACERWC that are positive about childhood and adolescent sexuality.

As the table shows, the CRoC has used language that recognizes sexual agency of children such as: 'First sexual intercourse'; 'sexual activity of girls'; sexual behaviours of children that do not conform to societal expectations; deal positively and responsibly with their sexuality; and 'express their sexuality'. The CRoC also requests states to not criminalize adolescents for consensual and non-exploitative sexual conduct.

The AU treaty monitoring bodies have also used some progressive language. The Joint General Comment of the ACHPR and the ACERWC on 


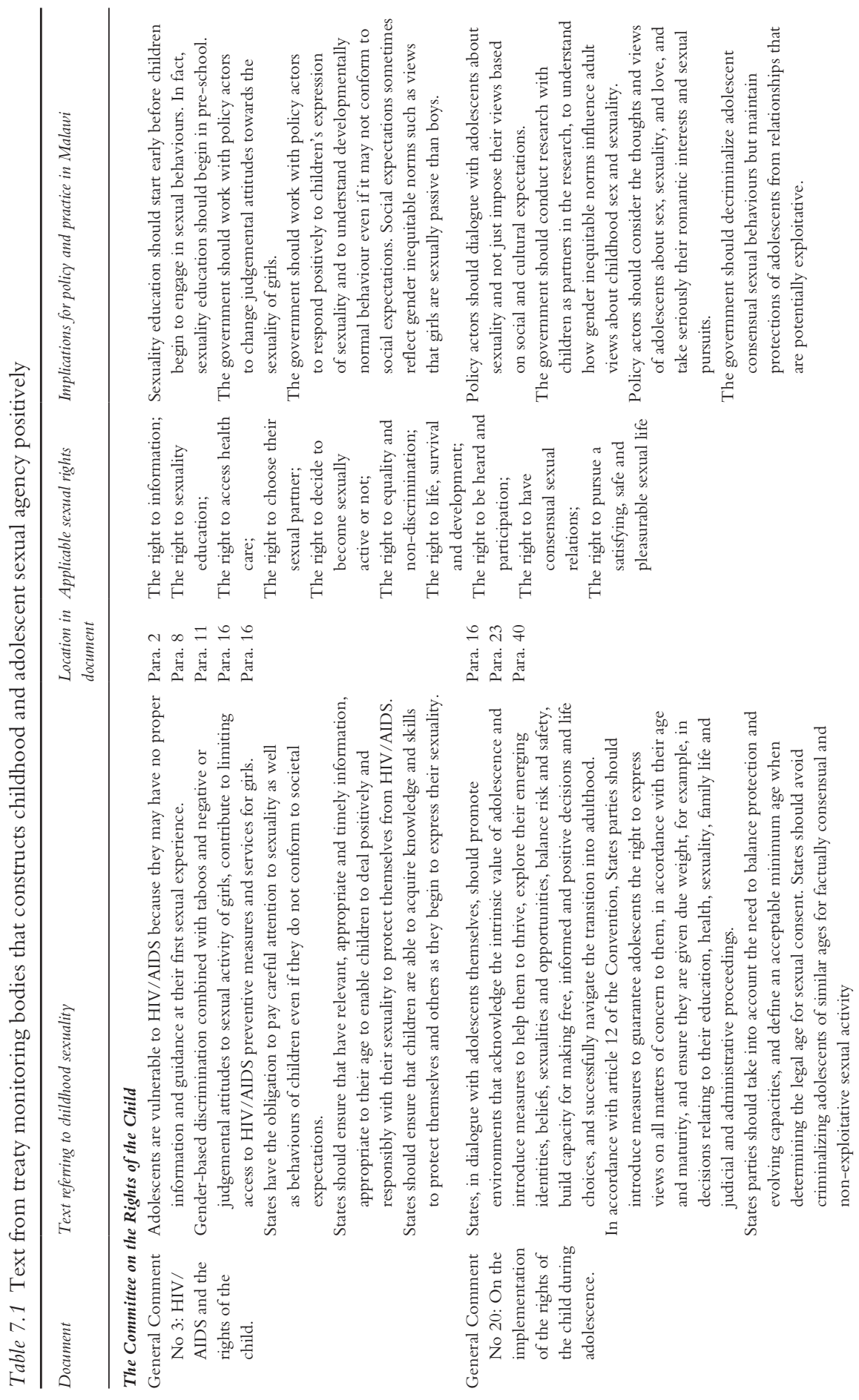



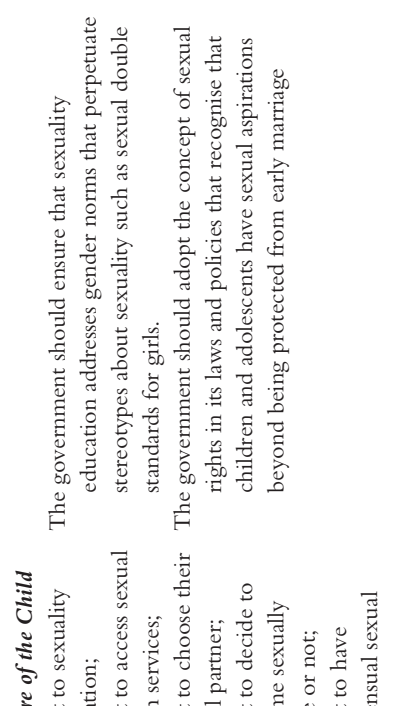

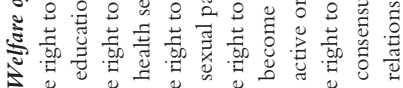

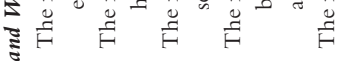

$\stackrel{5}{3}$

ะั

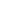

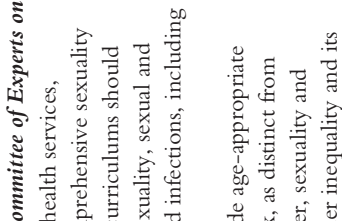

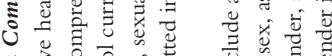

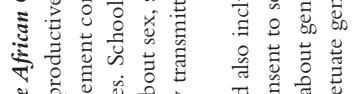

₹

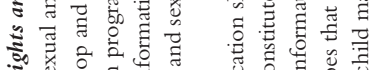

¿

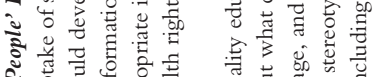

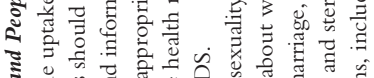

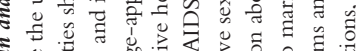

इ

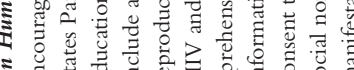

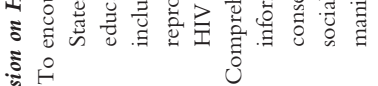

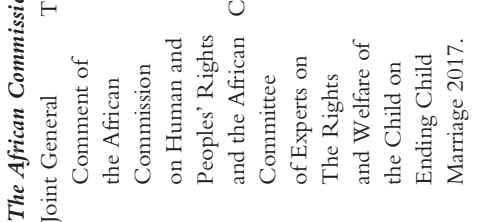


Child Marriage (JGC on Child Marriage) encourages states to implement comprehensive sexuality education (CSE) that includes sexuality and sexual and reproductive health rights. It recommends that CSE should include consent to sex and provide information about gender and sexuality and address the stereotypes that perpetuate gender inequalities. More of this language that constructs children and adolescents as having sexual agency should appear in such authoritative and interpretive documents, to guide states to create legal and policy environments in which children learn about sexuality as a positive aspect of their human development.

\section{The importance of decriminalizing adolescent sexual conduct}

In Malawi, sex between consenting adolescents is criminalized under Section 138 of the Penal Code. Criminalizing adolescent consensual sexual conduct is an extreme form of denying that children and adolescents are sexual beings. Laws criminalizing child consensual sexual conduct are a form of violence. Social expectations supported by gender inequitable norms tend to influence the design and implementation of these laws. Criminalising adolescent consensual sex has a negative impact on the sexual rights of adolescents. Such criminal laws also serve to maintain attitudes toward adolescents that are rooted in gender inequitable norms. A case in point is Martin Charo $v$ Republic decided by the High Court of Kenya, which is described below.

Kenya, like most countries in sub-Saharan Africa including Malawi, adopted colonial sexual consent laws that restricted sexual conduct with children and adolescents of below a certain age. These so-called 'age of consent' laws were premised on gender stereotypes that regarded girls as sexually passive and in need of protection from men and boys whose active sexuality posed a threat to the virginity of girls. ${ }^{45}$ Even after Kenya transformed its sexual offences law to align it with the rights of the child and gender equality, gender inequitable norms still influence how legal institutions and actors perceive and respond to adolescent sexuality.

In Charo, the appellant, a 23-year-old male, had sexual intercourse with a girl of 14. A magistrate's court convicted him of the offence of defilement under section 8(1)(3) of the Sexual Offences Act 3 of 2006 (Sexual Offences Act) of Kenya and sentenced to imprisonment for 20 years. On appeal, the High Court quashed his conviction and sentence. The court's decision hinged on the interpretation and application of sections 8(5) and 8(6) of the Sexual Offences Act. Under section 8(5) of the Sexual Offences Act, it is a defence if an accused person proves that the complainant deceived him or her into believing that he or she was over the age of 18 , and if the accused person reasonably believed that the person was above the age of 18. According to section 8(6), the court should in determining the accused person's belief envisaged under section $8(5)$, consider all circumstances including the steps the accused person took to learn the age. The defence argued that by voluntarily leaving her home 
and going to the home of the appellant for the purposes of having sexual intercourse with the appellant, the complainant behaved, deceptively, like an adult. The court allowed the defence to stand and quashed the conviction.

What is interesting for this chapter is the judge's belief about the sexual conduct of girls. The judge restated the aim of the defilement provisions in these terms: 'It is the law that a child below the age of 18 years cannot consent to sex'. He went on to express the opinion that: 'However, where the same child under 18 years who is protected by the law opts to go into men's houses for sex ... why should the court conclude that such a person was defiled'. The judge believed that the 14-year-old girl behaved like an adult. In the view of the judge, 'although PW1 was a young lady aged 14 years; she was behaving like a full grown up woman who was already engaging and enjoying sex with men'. Further, the judge thought that: 'Children are not meant to enjoy sex', and that 'where the child behaves like an adult and willingly sneaks into men's houses for purposes of having sex, the court ought to treat such a child as a grown-up who knows what she is doing'. In the judge's reasoning, the sexual behaviour of the girl was against social norms about how a girl is supposed to behave sexually. The wording of the law provided the opportunity for the judge to interpret the legal provisions to ascribe meanings that reflected societal gender norms and expectations about a girl's sexual behaviour.

Sexual offences laws that criminalize adolescent consensual sexual conduct are often vehicles for communicating negative and gendered messages about sexuality to children. It is difficult to imagine circumstances in which such laws would be compatible with the rights of the child. For instance, Section 138 of Malawi's Penal Code constructs the girl, but not the boy, as the object of protection from harmful sexual intercourse. This provision is more aligned to gender stereotypical and inequitable norms than it is to the GEA and constitutional values.

\section{Conclusion}

Though Malawi has a robust legal framework to address gender inequality, the social environment does not support children to develop positive sexual behaviours and practices. However, Section 19 of the Gender Equality holds promise because, as has been argued in this chapter, it ought to be interpreted to promote sexual rights of children and adolescents, including the right to sexuality education, the right to decide to be sexuality active or not and the right to choose a sexual partner.

To support creating a positive environment for sexuality development of children, this author recommends that Malawi should include a section on sexuality in the National Policy on Early Childhood Development (ECD) to guide ECD practitioners to implement laws and policies in a manner that recognizes the sexual agency of children. For instance, respect of the right of the child to be heard means that ECD practitioners are obligated to take seriously children's views about sex, sexuality, love and romance, because 
these are important for children, and they form the basis for sexual conduct that has a lasting impact on their sexual development and sexual health trajectories.

Another recommendation is that CSE should start early in pre-school. The design of CSE should be to address not only what adults believe children should learn, but to also enable children to critically engage with what they already learn, and to address gender discriminatory values about sexuality prevalent in society. It is, therefore, crucially important to build the capacity of educators to effectively engage with children and adolescents on sexuality and gender.

There has been little guidance from treaty monitoring bodies especially the ACERWC on how to implement the ACRWC to promote sexual rights of children, beyond protecting them from harms of sexual conduct and early marriage. The JGC on Child Marriage is, however, progressive because it has called on African states to provide CSE that includes consent to sex and information about sexuality. An important entry point for the ACERWC to further promote child rights relating to sexuality would be to encourage states to review age of consent laws that punish children and adolescents for engaging in normative consensual sexual conduct. Such laws have a negative impact on childhood sexuality development and gender equality in Africa, for the reasons discussed in this chapter. It would be of tremendous significance and impact if the ACERWC could analyze age of consent laws and guide states to align their laws and policies with the rights of the child and the advancement of gender equality in accordance with Africa's Agenda for Children 2040.

\section{Notes}

$1 \mathrm{~K}$ Mmari et al 'Exploration of gender norms and socialization among early adolescents: The use of qualitative methods for the global early adolescent study' (2017) 61 Journal of Adolescent Health s13.

$2 \mathrm{R}$ Blum et al 'It begins at 10: How gender expectations shape early adolescence around the world' (2017) 61 Journal of Adolescent Health; Global Early Adolescent Study 'Blantyre baseline report' (2018) https://www.geastudy.org/new-blog/blantyre-baseline-report (accessed 10 October 2019).

3 V Chandra-Mouli et al 'Implications of the global early adolescent study's formative research findings for action and for research' (2017) 61 The Journal of Adolescent Health s5.

4 D Bhana 'Love, sex and gender: Missing in African child and youth studies' (2017) 42 Africa Development 245.

5 B Bello et al 'Adolescent and parental reactions to puberty in Nigeria and Kenya: A Cross-cultural and intergenerational comparison' (2017) 61 Journal of Adolescent Health s40-s41; R Limaye et al 'Talking about sex in Malawi: toward a better understanding of interpersonal communication for HIV prevention' (2012) 1 Journal of Public Health Research 122-123.

6 D Bhana "CHAPTER TEN: "Show me the panties": Girls play games in the school ground' (2005) 245 Counterpoints. Bhana's article shows how gender and sexuality are expressed amongst children in play in school cultures.

7 According to the GEAS Blantyre report, $65 \%$ of boys and $56 \%$ of girls experienced being victims of IPV while $54 \%$ of boys and $45 \%$ of girls experience being perpetrators of IPV. 


\section{Godfrey Dalitso Kangaude}

8 S Igras et al 'Investing in very young adolescents' sexual and reproductive health' (2014) 9 Global Public Health 558.

9 C Lane et al 'Why we must invest in early adolescence: Early intervention, lasting impact' (2017) 61 The Journal of Adolescent Health s10. See also V Woog \& A Kaggesten The sexual and reproductive health needs of very young adolescents aged 10-14 in developing countries: What does the evidence show? (2017).

10 J Kato-Wallace \& R Levtov 'Very young adolescence 2.0: A curriculum to promote gender equality and sexual and reproductive health' (Washington, DC; Blantyre: Promundo US; College of Medicine (Malawi), 2018) 4-7.

11 L Carpenter \&J Delamater 'Studying gendered sexualities over the life course:A conceptual framework' in LM Carpenter \& J Delamater (eds) Sex for life: From virginity to viagra, how sexuality changes throughout our lives (2012) 25; P Banati \& J Lansford 'Introduction: Adolescence in a global context' in J Lansford \& P Banati (eds) Handbook of adolescent development research and its impact on global policy (2018) 5 .

12 Banati \& Lansford (n 12); Carpenter \& Delamater (n 12) 25.

13 A Moore et al 'Coerced first sex among adolescent girls in sub-Saharan Africa: Prevalence and context' (2007) 11 African Journal of Reproductive Health 78; M Becker et al 'Vulnerabilities at first sex and their association with lifetime gender-based violence and HIV prevalence among adolescent girls and young women engaged in sex work, transactional sex, and casual sex in Kenya' (2018) 79 JAIDS Journal of Acquired Immune Deficiency Syndromes 299.

14 M Johnson et al 'Insights on adolescence from a life course perspective' (2011) 21 Journal of Research on Adolescence 274.

15 G Kangaude 'Adolescent sex and 'defilement' in Malawi law and society' (2017) 17 African Human Rights Law Journal 534.

16 Johnson et al (n 15) 274.

17 Carpenter \& Delamater (n 12) 32.

18 S De Meyer et al "Boys should have the courage to ask a girl out": Gender norms in early adolescent romantic relationships' (2017) 61 Journal of Adolescent Health 45-46.

19 D Bhana Gender and childhood sexuality in primary school (2016) 28.

20 P Mudhovozi et al 'Adolescent sexuality and culture: South African mothers' perspective' (2012) 16 African Sociological Review/Revue Africaine de Sociologie 121. However, in some cultures, sexuality is talked about in other spaces such as initiation rites.

21 N Fairclough Language and power (2001) 33.

22 P Bourdieu Outline of a theory of practice (1977) 79.

23 W Simon \& J Gagnon Sexual conduct:The social sources of human sexuality (2017) (2nd ed) 6.

24 Simon \& Gagnon (n 24) 21.

25 As above.

26 As above

27 Simon \& Gagnon (n 24) 24.

28 Simon \& Gagnon (n 24) 27.

$29 \mathrm{~S}$ Basu et al 'Learning to be gendered: Gender socialization in early adolescence among urban poor in Delhi, India, and Shanghai, China' (2017) 61 Journal of Adolescent Health s28.

30 Simon \& Gagnon (n 24) 28.

31 As above.

32 Simon \& Gagnon (n 24) 25.

33 Limaye et al (n 6) 123.

34 F Muhanguzi 'Gender and sexual vulnerability of young women in Africa: Experiences of young girls in secondary schools in Uganda' (2011) 13 Culture, Health \& Sexuality 716.

35 Muhanguzi (n 35) 718.

36 F Leach et al An investigative study of the abuse of girls in African schools (2003) 80. An example of violence is that boys would write aggressive 'love' letters to girls, including threats to the girl if she does no respond positively to the sexual advances of the boy.

37 D Tolman 'Doing desire: Adolescent girls' struggles for/with sexuality' (1994) 8 Gender and Society. 
38 Evidence to Action Project Evaluation of youth-friendly health services in Malawi (2014) 174.

39 M Grant 'Girls' schooling and the perceived threat of adolescent sexual activity in rural Malawi' (2012) 14 Culture, Health \& Sexuality 77.

40 A Miller 'Sexual but not reproductive: Exploring the junction and disjunction of sexual and reproductive rights' (2000) 4 Health and Human Rights 87.

41 A Coates et al 'The Holy See on sexual and reproductive health rights: conservative in position, dynamic in response' (2014) 22 Reproductive Health Matters 117-118.

42 International Service for Human Rights, Majority of GA Third Committee unable to accept report on the human right to sexual education (2010) https://www.ishr.ch/news /majority-ga-third-committee-unable-accept-report-human-right-sexual-education (accessed 19 April 2020).

43 S Angelides 'Feminism, child sexual abuse, and the erasure of child sexuality' (2004) 10 GlQ: A Journal of Lesbian and Gay Studies 142.

44 T Wijaya Mulya 'Contesting the dominant discourse of child sexual abuse: Sexual subjects, agency, and ethics' (2018) 22 Sexuality \& Culture 753-754.

45 Kangaude (n 16) 537.

\section{References}

Angelides, S 'Feminism, child sexual abuse, and the erasure of child sexuality' (2004) 10 GlQ: A Journal of Lesbian and Gay Studies 141.

Banati, P \& Lansford, J 'Introduction: Adolescence in a global context' in Lansford, J \& Banati, P (eds) Handbook of adolescent development research and its impact on global policy (Oxford University Press 2018).

Basu, S, Zuo, X, Lou, C, Acharya, R \& Lundgren, R 'Learning to be gendered: Gender socialization in early adolescence among urban poor in Delhi, India, and Shanghai, China' (2017) 61 Journal of Adolescent Health S24.

Becker, M, Bhattacharjee, P, Blanchard, J, Cheuk, E \& Isaac, S 'Vulnerabilities at first sex and their association with lifetime gender-based violence and HIV prevalence among adolescent girls and young women engaged in sex work, transactional sex, and casual sex in Kenya' (2018) 79 JAIDS Journal of Acquired Immune Deficiency Syndromes 296.

Bello, B, Fatusi, A, Adepoju, O, Maina, B \& Kabiru, C 'Adolescent and parental reactions to puberty in Nigeria and Kenya: A cross-cultural and intergenerational comparison' (2017) 61 Journal of Adolescent Health S35.

Bhana, D "CHAPTER TEN: "Show me the panties": Girls play games in the school ground' (2005) 245 Counterpoints 163.

Bhana, D Gender and childhood sexuality in primary school (Singapore: Springer 2016).

Bhana, D 'Love, sex and gender: Missing in African child and youth studies' (2017) 42 Africa Development 251.

Blum, R, Mmari, K \& Moreau, C 'It begins at 10: How gender expectations shape early adolescence around the world' (2017) 61 Journal of Adolescent Health S3

Bourdieu, P Outline of a theory of practice (Cambridge University Press 1977).

Carpenter, L \& Delamater, J (eds) 'Studying gendered sexualities over the life course: A conceptual framework' In Carpenter, LM \& Delamater, J Sex for life: From virginity to viagra, how sexuality changes throughout our lives (NYU Press 2012).

Chandra-Mouli, V, Plesons, M, Adebayo, E, Amin, A \& Avni, M 'Implications of the global early adolescent study's formative research findings for action and for research' (2017) 61 The Journal of Adolescent Health S5.

Coates, A, Hill, P, Rushton, S \& Balen, J 'The Holy See on sexual and reproductive health rights: Conservative in position, dynamic in response' (2014) 22 Reproductive Health Matters 114. 


\section{Godfrey Dalitso Kangaude}

De Meyer, S, Kågesten, A, Mmari, K, McEachran, J \& Chilet-Rosell, E “"Boys should have the courage to ask a girl out": Gender norms in early adolescent romantic relationships' (2017) 61 Journal of Adolescent Health S42.

Evidence to Action Project Evaluation of youth-friendly health services in Malawi (Evidence to Action Project 2014).

Fairclough, N Language and power (Routledge 2001).

Global Early Adolescent Study 'Blantyre baseline report' (2018) https://www.geastudy.org /new-blog/blantyre-baseline-report.

Grant, M 'Girls' schooling and the perceived threat of adolescent sexual activity in rural Malawi' (2012) 14 Culture, Health \& Sexuality 73.

Igras, S, Macieira, M, Murphy, E \& Lundgren, R 'Investing in very young adolescents' sexual and reproductive health' (2014) 9 Global Public Health 555.

Johnson, M, Crosnoe, R \& Elder Jr, G 'Insights on adolescence from a life course perspective' (2011) 21 Journal of Research on Adolescence 273.

Kangaude, G 'Adolescent sex and 'defilement' in Malawi law and society' (2017) 17 African Human Rights Law Journal 527.

Kato-Wallace, J \& Levtov, R Very young adolescence 2.0: A curriculum to promote gender equality and sexual and reproductive health (Promundo-US College of Medicine Malawi 2018).

Lane, C, Brundage, C \& Kreinin, T 'Why we must invest in early adolescence: Early intervention, lasting impact' (2017) 61 The Journal of Adolescent Health S10.

Leach, F, Fiscian, V, Kadzamira, E, Lemani, E \& Machakanja, P An investigative study of the abuse of girls in African schools (Department for International Development 2003).

Limaye, R, Rimal, R, Mkandawire, G, Roberts, P \& Dothi, W 'Talking about sex in Malawi: Toward a better understanding of interpersonal communication for HIV prevention' (2012) 1 Journal of Public Health Research 117.

Malawi Law Commission Report of the Law Commission on the development of the Gender Equality Act (Malawi Law Commission 2011).

Miller, A 'Sexual but not reproductive: Exploring the junction and disjunction of sexual and reproductive rights' (2000) 4 Health and Human Rights 68.

Mmari, K, Blum, R, Atnafou, R, Chilet, E \& de Meyer, S 'Exploration of gender norms and socialization among early adolescents: The use of qualitative methods for the global early adolescent study' (2017) 61 Journal of Adolescent Health S12.

Moore, A, Awusabo-Asare, K, Madise, N, John-Langba, J \& Kumi-Kyereme, A 'Coerced first sex among adolescent girls in sub-Saharan Africa: Prevalence and context' (2007) 11 African Journal of Reproductive Health 62.

Mudhovozi, P, Ramarumo, M \& Sodi, T 'Adolescent sexuality and culture: South African mothers' perspective' (2012) 16 African Sociological Review/Revue Africaine de Sociologie 119.

Muhanguzi, F 'Gender and sexual vulnerability of young women in Africa: Experiences of young girls in secondary schools in Uganda' (2011) 13 Culture, Health \& Sexuality 713.

Simon, W \& Gagnon, J Sexual conduct: The social sources of human sexuality (2nd ed) (Routledge 2017).

Tolman, D 'Doing desire: Adolescent girls' struggles for/with sexuality' (1994) 8 Gender and Society 324.

Wijaya Mulya, $T$ 'Contesting the dominant discourse of child sexual abuse: Sexual subjects, agency, and ethics' (2018) 22 Sexuality \& Culture 740.

Woog, V \& Kågesten, A The sexual and reproductive health needs of very young adolescents aged 10-14 in developing countries: What does the evidence show? (Guttmacher Institute 2017). 